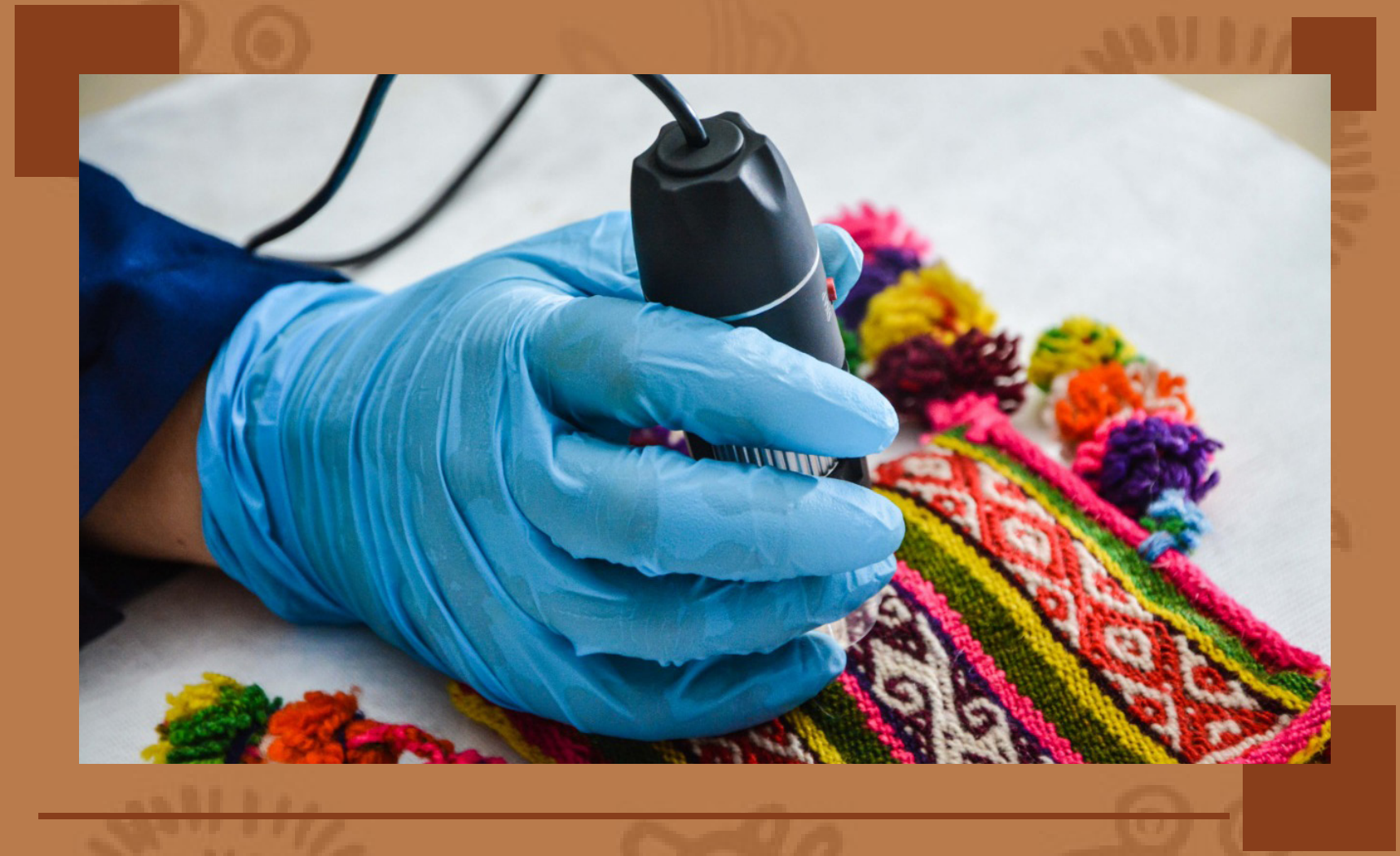

Sociedad de la incertidumbre Parte II. Secuelas y daños colaterales de una pandemia, Covid-19 


\section{Sociedad de La Incertidumbre Parte II. Secuelas y Daños Colaterales De Una Pandemia, Covid-19}

Society of Uncertainty Part II. Aftermath and Collateral Damage of a Covid-19 Pandemic

\section{Xavier Eduardo Perlaza Rodríguez}

Sociólogo por la Universidad Estatal Salvador Allende de Guayaquil, Ecuador. ID Orcid https://orcid.org/0000-0002-6025-7081

xaviereduardoperlaza@gmail.com
Recibido: 07-05-2021

Aceptado: 21-05-2021

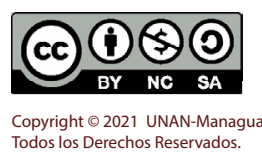

\section{Resumen}

El presente ensayo plantea el escenario de incertidumbre que atraviesa América Latina a raíz del aparecimiento de la pandemia de COVID19, poniendo la mirada en algunas particularidades que si bien es cierto ya se venían desmejorando los impactos producidos por la pandemia han contribuido a la profundización de ese desmejoramiento. Para esto es necesario hacer un recorrido por algunos aspectos como: la composición demográfica en la región, el tratamiento no adecuado que se le ha dado a la información en cuanto a los contagios de los distintos grupos étnicos con énfasis en población indígena y Afrodescendientes, las condiciones de habitabilidad y la relación de esta con los contagios de la Covid19, el impacto en la economía (PIB) y en los sistemas educativos de la región. En otro momento del ensayo se hace un análisis de la situación en Ecuador, tomando varios de los elementos que forman parte de la generalidad (AL), pero distinguiéndose con el periodo electoral que atravesó el país sudamericano. Por último el documento hace un llamado a América Latina a enfrentar la crisis sanitaria de forma más articulada, y que esto permita al continente salir del escenario de incertidumbre para emprender el camino hacia la certeza.

Palabras claves: Incertidumbre, Pandemia, Sociedad, Desafíos, Economía.

\section{Abstract}

This essay presents the scenario of uncertainty that Latin America is going through as a result of the emergence of the COVID19 pandemic, looking at some particularities that, although it is true, had already been worsening the impacts produced by the pandemic have contributed to the deepening of this deterioration. For this, it is necessary to take a tour of some aspects such as: the demographic composition in the region, the inadequate treatment that has been given to the information regarding the infections of the different ethnic groups with emphasis on the indigenous and Afro-descendant population, the habitability conditions and the relationship of this with the contagions of Covid19, the impact on the economy (GDP) and on the educational systems of the region. At another point in the essay, an analysis of the situation in Ecuador is made, taking several of the elements that are part of the generality (AL), but distinguishing itself with the electoral period that the South American country went through. Finally, the document calls on Latin America to face the health crisis in a more articulated way, and that this allows the continent to leave the scenario of uncertainty to embark on the path to certainty.

Keywords: Uncertainty, Pandemic, Society, Challenges, Economy. 


\section{Introducción}

La región (América Latina y el Caribe) a poco más de un año del aparecimiento de la pandemia de Covid19 ( 25 de febrero 2020 se detectó el primer caso de coronavirus en Brasil) y de los impactos producidos por la misma, se enfrenta a las secuelas y daños colaterales que esta situación sanitaria trajo consigo. Evidentemente dichas circunstancias y por distintas razones han afectado a unos países más que a otros, afectaciones que han iniciado en el corto plazo y que sin duda al largo plazo también se empezaran a evidenciar no solo en el aspecto sanitario y económico sino en el campo y composición demográfica de la región así como en los ámbitos étnicos, educativos y de acceso a la vivienda y saneamiento, mismos que han jugado un papel trascendente en la actual crisis sanitaria producida por la pandemia. Las brechas de las desigualdades se ampliaron aún más en América Latina y el Caribe, por ejemplo y para hacer referencia a uno de los aspectos antes mencionados.

Las desigualdades se ven frecuentemente invisibilizadas por problemas relacionados con el acceso a los datos de personas que se han contagiado y que han fallecido a causa de Covid19. De los países de América Latina y el Caribe solo Brasil y Colombia presentan información de casos de contagios y fallecimientos de personas Afrodescendientes (CEPAL, Panorama Social de América Latina, 2020, Pág. 14).

Otro tema que probablemente sea el que mayoritariamente tenga todas las luces apuntándole es la economía. Se estima que el PIB (Producto Interno Bruto) de la totalidad de los países de la región caerá en un $7,7 \%$ y como secuela de esto la tasa de desocupación aumentará en unos 2,6 puntos porcentuales. Esto presenta un desafío para la región ya que la matriz de desigualdad parece interminable y sus gigantescas brechas parecen no cerrarse, por tanto es necesario construir un camino de cierre de las brechas y que dicho proceso se plantee de forma sostenible. Los pasos que se tendrán que ir dando deben ser contundentes y muy bien estructurados a fin de ir superando la crisis sanitaria, pero también las otras crisis que se agudizaron con el aparecimiento del Covid-19.

El presente documento procurará hacer una revisión de algunos aspectos que se presentan como mecanismos generadores de incertidumbre y es necesario que puedan ser examinados y abordados por los gobiernos de toda la región. Cabe señalar que revisará lo que ocurre en América Latina a partir del surgimiento de la pandemia y los efectos producidos por esta en los aspectos anteriormente señalados. Así también se propone ubicar el lente en Ecuador. Para esto se desarrollarán tres momentos de análisis en el caso del territorio ecuatoriano: el primer momento estará centrado en lo que está ocurriendo actualmente con la pandemia, específicamente de la gestión que se está llevando a cabo con el proceso de vacunación hacia la población, el segundo tendrá que ver con la crisis económica que el país sudamericano atraviesa a partir de la caída catastrófica de su $\mathrm{PIB}$, el tercer momento tiene que ver con el escenario político (Elecciones presidenciales) mismo que se ha constituido en un mecanismo generador de confusión e incertidumbre para las/os ecuatorianos. 


\section{Desarrollo}

\section{América Latina y El Escenario De Incertidumbre Agravado Por La Crisis Sanitaria.}

A pesar de las medidas formuladas a los Estados por parte de los organismos internacionales como Organización Mundial de la Salud (OMS) y la Organización Panamericana de la Salud (OPS), dichas disposiciones contemplan como principal característica la homogeneidad. Es decir se dispuso desde estás instituciones y teniendo como entes operadores a los Estados, se plantearon medidas idénticas para todos los países (confinamiento de la población, uso de mascarillas, distanciamiento social y lavado de manos) como factores fundamentales para detener la propagación del virus.

La pandemia de Covid-19 ya lleva más de un año desde su aparecimiento, es necesario realizar observaciones a dichas disposiciones, claro está se conoce que las mismas son planteadas por expertos y siendo así producirían el resultado esperado que era evitar los contagios. Entonces es importante señalar que; siendo el carácter de las medidas absolutamente homogéneo estas fueron aplicadas a países y ciudadanos totalmente heterogéneos que los distinguen, la cultura, la idiosincrasia, las condiciones y acceso que tienen los países así como sus sociedades a la tecnología, la educación a los sistemas de salud, agua y saneamiento, vivienda, producción, empleo, entre otros aspectos que marcan una diferencia en ocasiones altamente asimétricas de un país a otro de una ciudad a otra.

Conociendo que el comportamiento del virus no discrimina ningún tipo de diferencia, sino que, desde el punto de vista de la transmisibilidad cualquiera puede contagiarse, da igual si una persona vive en países desarrollados como Alemania o Japón o en países subdesarrollados como en el caso de América Latina. Pero la forma de enfrentamiento de la crisis sanitaria, el acatamiento de las medidas dispuestas tanto por las instituciones internacionales y los gobiernos, la velocidad o lentitud para salir de dicha crisis, es allí donde se puede notar el escenario anómalo entre un continente y otro, entre un país y otro. Los países de la región se han visto en la disyuntiva de lograr establecer ecuanimidad entre salud y economía, siendo esto una tarea compleja para los gobiernos Latinoamericanos. La búsqueda de dicho equilibrio se ha convertido en el principal escenario de incertidumbre para toda la región, ya que: cómo se puede mantener a una población confinada, cuando desde el aspecto productivo y de trabajo hay una alta tasa de informalidad laboral concentrada en los países del continente.

Muchos países de la región tienen altos niveles de informalidad. Un promedio de $56 \%$ de los trabajadores estaban en el sector informal de la economía antes del coronavirus, y estimaciones recientes predicen que esta cifra subirá a un $62 \%$ debido a los efectos de la pandemia. Sin embargo, hay países que ya enfrentaban niveles de informalidad mucho más altos desde antes de la crisis, como es el caso de Honduras $84 \%$, Nicaragua $77 \%$ Guatemala $76 \%$ y Bolivia $71 \%$ (Bentata, Pral, \& Ripani Laura, 2020)

Frente a condiciones como estas no resultas mucho antes del aparecimiento de la crisis sanitaria global, América Latina ha tenido que hacerle frente a esta pandemia. Aproximadamente 158 millones de personas de acuerdo con datos de la Organización Internacional del Trabajo (OIT) ejercen sus actividades laborales en condiciones de informalidad. 
Este aspecto obliga de manera recurrente a las personas tener que salir a las calles de sus ciudades a buscar la forma de generar los recursos económicos necesarios para poder sustentar a sus familiares día a día, ya que el escenario de informalidad no representa para la mayoría de estas personas ingresos fijos, sino que los ingresos económicos de estas familias se ven sujetos a lo que diariamente puedan generar. Por ese hecho la medida de confinamiento es todo un desafío para este sector.

Es necesario señalar que varios países implementaron acciones de contención dirigidas a las familias más pobres y vulnerables, a fin de evitar la propagación del contagio, pero asimismo se conoce que no fue suficiente, la precariedad e incertidumbre financiera a la que quedaron expuestas millones de personas a rebasado las posibilidades planteadas por los gobiernos para procurar contener el agravamiento y profundización de la pobreza a la que se enfrentan familias enteras en todo el continente. Por otro lado y en la necesidad de seguir mostrando cómo las medidas homogéneas impuestas a sociedades heterogéneas generan resistencia e incertidumbre, es válido mencionar también el aspecto de las interacciones sociales restringidas a partir del proceso de cuarentena o confinamiento de la población. Evidentemente las formas de relacionamiento y de interacción social entre, por ejemplo, los países Latinoamericanos y algunos de Asia y de Europa lógicamente los comportamientos culturales son totalmente distintos.

En el caso de la región las personas están acostumbradas a moverse en círculos sociales mucho más abiertos que van desde la familia, las amistades, el trabajo y otros grupos que se van formando, por tanto se reduce la posibilidad de interacciones sociales más cerradas. Al implementarse la medida de confinamiento esto de alguna forma trastocó ese rasgo identitario propio de la cultura Latinoamericana, entonces se llegó a convertir en un elemento causante de resistencia, mismo que para la sociedad de la región aún le cuesta asumirlo. No siendo este el caso de la mayoría de países Asiáticos y algunos de Europa, donde los círculos de relacionamiento y de interacción social son mucho más estrechos, donde también políticamente hablando estas sociedades son más verticalizadas y menos horizontales en el caso de países de Asia por ejemplo. Siendo así sería menos complejo para esas poblaciones enfrentarse a medidas de cuarentena o confinamiento.

Otro aspecto social trascendente es la urbanización que refleja el continente y de su alta implicación y/o relación con la propagación de los contagios por corona virus es ir tocando un aspecto que quizás al inicio de la pandemia y como resultado del desconocimiento de su manifestación, comportamiento e impactos, probablemente no se logró en su momento establecer un marco de relacionamiento si podría decirse así de las dos variables.

Actualmente el $81 \%$ de la población del continente vive en zonas consideradas como urbanas, esto ha generado condiciones de "metropolización" en varias ciudades de América Latina. Por ejemplo el $35 \%$ de la población vive en ciudades que están por encima del millón de habitantes, resaltando algunas megalópolis en el caso de Buenos Aires, Lima, ciudad de México, Río de Janeiro y Sao Paulo, estás ciudades llegan a tener entre su población un poco más de diez millones de habitantes (CEPAL, Panorama Social de América Latina, 2020). 
Este crecimiento y ocupación de la población hacia los conos urbanos ha generado el aparecimiento de otros problemas no resueltos a lo largo del continente, el hacinamiento y los déficits de vivienda que se pueden observar, así también el acceso a agua y saneamiento se colocan como manifestantes en contra punto por ejemplo de lo solicitado por la Organización Mundial de la salud en cuanto a las medidas de confinamiento, lavado de manos y distanciamiento social como mecanismos para evitar los contagios.

Los datos en este sentido demuestran la dificultad que miles de familias y hogares de América Latina han tenido que enfrentar en este sentido debido a las circunstancias expuestas anteriormente. Para evidenciar la complejidad de esta situación se tomaran dos datos: el primero será el de la población de más de dos personas durmiendo en un dormitorio, la información demuestra que el $30,2 \%$ de los hogares y familias presentan esa condición. Y esto se vuelve mucho más crítico cuando se trata de las personas pobres, ahí el dato indica que el 55,4\% de ese grupo poblacional está en esa condición. El segundo va en esa misma dirección, más de tres personas durmiendo en un dormitorio 18,4\% de los hogares y familias en la región atraviesan por esa problemática, así mismo como el primer dato en este también se demuestra que cuando se observa a los más pobres el porcentaje es superior $39,2 \%$ de este grupo viven en esa condición. Esto demuestra las circunstancias que las personas tienen que atravesar si alguien del cuadro familiar se contagia, la posibilidad de propagación de contagio es mucho más alta como resultado de la complejidad de hacinamiento.

Frente a todo esto es necesario pasar una mirada de la situación y condiciones que enfrentan los pueblos indígenas y los Afrodescendientes de la región. Las carencias y desigualdades que sufren los pueblos indígenas hacen que sean más vulnerables ante la pandemia.

El documento de informe Panorama Social de América Latina menciona que actualmente existen 58 millones de personas que son parte de estos pueblos, se estima según los datos que: más de 8 millones de indígenas experimentan carencias de acceso a agua potable en la vivienda, lo que les imposibilita poner en práctica el lavado frecuente de manos, medida esencial de prevención del contagio.

De acuerdo con la distribución de la población indígena y no indígena por nivel de vulnerabilidad en las condiciones de habitabilidad a nivel municipal, en Guatemala alrededor del $35 \%$ de la población indígena demuestra una condición crítica en cuanto a esta distribución y así mismo alrededor de un $48 \%$ se encuentra en un nivel de alta vulnerabilidad. Otro de los países de la región donde también esta distribución demuestra condiciones alarmantes es Colombia, alrededor de un $22 \%$ de la población indígena está en condiciones críticas según la distribución de habitabilidad a nivel Municipal, seguido a ese dato un $45 \%$ se encuentran en un nivel de alta vulnerabilidad en ese sentido. En definitiva es todo un desafío para este grupo poblacional enfrentar la pandemia con toda la carga de la desigualdad estructural y sistémica, las organizaciones y los líderes de los pueblos indígenas se ven abocados a acudir al uso de medicina ancestral a fin de evitar así los contagios y poder brindar un mejor cuidado a aquellos que se han contagiado.

En cuanto a la población Afrodescendientes actualmente son 134 millones de personas de este grupo étnico que viven en el continente y así como los pueblos indígenas también tienen que hacerle frente a esta emergencia sanitaria con un sinnúmero de desventajas. 
El racismo estructural e institucional empuja hacia los niveles de desigualdad más precarios a esta población, limitándosele el acceso al empleo formal, el acceso a los sistemas educativos, al sistema de salud, provocando que sea también toda una odisea lidiar con la pandemia pero así también con las medidas sanitarias impuestas por los países.

Para ir cerrando la ventana que se abrió a fin de lograr asomarnos y poder observar las cosas que están ocurriendo en nuestra región se ubicarán dos aspectos más que son necesarios poderlos tratar.

Más de medio millón de personas fallecieron en todo el continente como resultado de no haber logrado superar la enfermedad provocada por la pandemia. Esto demuestra una afectación en el campo demográfico de la región ya que tanto el nivel de mortalidad y de esperanza de vida se han visto trastocados por el Covid19. Los niveles de esperanza de vida dependerán al menos de dos factores: el primero, de cuánto tiempo más dure la pandemia y el segundo de las posibilidades que tengan las personas para vacunarse. Otro ámbito que ha sido socavado y que guarda relación con la demografía Latinoamericana es el de la fecundidad, probablemente se observará una disminución en esta tasa, dado los impactos y secuelas que la pandemia ha producido en la economía y productividad familiar, siendo así es probable que muchas parejas decidan postergar el proceso de maternidad y paternidad dada la incertidumbre económica por la que se está atravesando.

El sistema educativo es otro de los aspectos que recibió los impactos provocados por la emergencia sanitaria, de acuerdo con la información de CEPAL, 32 países cerraron sus instituciones educativas viéndose afectados un poco más de 165 millones de estudiantes. El cierre de los establecimientos educativos trajo consigo la necesidad de alguna forma no perder los siguientes meses de estudio a partir del Covid-19.

En ese sentido las instituciones educativas emprendieron el proceso de continuidad académica por medio del internet, la televisión y la radio. Pero estas alternativas que aparecerían como una posible solución para la continuidad escolar se tornan también en desventajas para otros, sobre todo para aquellos estudiantes que ya presentaban ciertas desventajas en relación a otros, es decir el no acceso a internet y otras circunstancias han imposibilitado de alguna forma que muchos estudiantes no puedan continuar con su proceso de formación. Así también aquellos grupos etarios que estaban por iniciar su ciclo formativo y debido a que el sistema en línea no estaba preparado metodológicamente para poder enseñar, estos grupos de estudiantes en su gran mayoría han tenido que postergar su formación. La crisis aumenta el riesgo de abandono escolar, según datos de la UNESCO 24 millones de estudiantes de 180 países de todos los niveles educativos están en riesgo de retomar sus estudios después de la crisis. En el caso de Latinoamérica son 3 millones que corren ese riesgo.

\section{¿Qué está pasando en Ecuador?}

Ecuador como se mencionó en uno de los párrafos de este texto es uno de los países de América Latina que está dentro de ese marco de los territorios más azotados por la pandemia de Covid-19. Lo sucedido entre marzo y abril del año 2020 dejó un escenario bastante lamentable y catastrófico en el país, siendo la Provincia del Guayas y su capital 
Guayaquil la más afectada por el brote de pandemia. Desde el punto de vista de condiciones de vida que actualmente atraviesan los ecuatorianos específicamente con lo relacionado al indicador de vivienda y hacinamiento, las cifras demuestran que existió un avance en este sentido por ejemplo si se toman datos del 2006.

En Ecuador para ese año el porcentaje de hacinamiento por hogar era del 22,0\%, para el año 2014 se observa una reducción significativa en este indicador del 12,7\%, cabe mencionar que en el área urbana la cifra es del $11,4 \%$ y en la zona rural esto se incrementa al 15,6\%. Al añadirse una división más a este indicador se puede identificar por ejemplo: en la región de la costa del país la cifra de hacinamiento es del $16,5 \%$, la sierra $8,1 \%$ y la Amazonía es del 18,5\% (INEC, Encuestas Condiciones de Vida ECV, 2015, págs. 32,33).

Como se mencionó al inicio se han producido avances en este sentido procurando mejorar estas condiciones para los ecuatorianos. Pero es evidente que aún hay mucho esfuerzo por realizar desde el Gobierno Central así como desde los Gobiernos Autónomos y Descentralizados (GAD) que también tienen dentro de sus competencias mejorar las condiciones de infraestructuras de sus territorios. Evidentemente condiciones como estás no resueltas se presentaron y siguen siendo factores de vulnerabilidad y de exposición al contagio de covid19 para las familias que viven en condiciones de hacinamiento, presentándose como un escenario antagónico a la hora por ejemplo del cumplimiento del distanciamiento físico que se debe manejar cuando alguien del cuadro familiar se ha contagiado. Sin dudas es una tarea que habrá que emprender con mucha fuerza y recursos en el país a fin de evitar la propagación de la pandemia. Actualmente los datos referentes a la covid19 muestran lo siguiente:

Se han tomado muestras para RT-PCR de 1.296 .909 personas hasta el momento de la elaboración del ensayo. Existen en todo el país 388.046 casos de contagios confirmados y 18.765 personas fallecidas. Las Provincias del país que evidencian un mayor porcentaje de contagio son Pichincha con el 35,2\%, Guayas con el 13,0\% y Manabí con el 7,5\% (MSP, Actualización de Casos de Coranavirus en Ecuador, 2021).

Otro aspecto altamente significativo para los ecuatorianos es el tema relacionado al proceso de vacunación, ya que la vacuna se muestra como ese elemento "esperanzador" de retorno a esa normalidad tan anhelada, no solo por los ecuatorianos sino también por todos los habitantes del planeta. El 8 de octubre del 2020 se constituyó el equipo encargado de desarrollar el Plan de Vacunación para el país, mismo que estuvo a cargo del Ministerio de Salud Pública (MSP). Este equipo sería el encargado de trazar la hoja de ruta a seguir para efectos del proceso de vacunación.

Entre las prioridades que se pueden anotar aparecen las siguientes: las negociaciones de las vacunas, determinación de la cantidad necesaria de la población que debe vacunarse para generar inmunidad en el país, escenarios y fases de suministros de vacunación. Asimismo se contemplaron factores como: el proceso de vacunación sería gratuito para la población ecuatoriana, la realización por fases contempladas en tres momentos: i) personal de salud, ii) personal de primera línea orden público y iii) personal docente del sector público. También se planificó que: para alcanzar el $60 \%$ de inmunización de la población es decir 10.5 millones de personas serían necesarias 21 millones de dosis, con eso 
se tendría la capacidad de vacunar a 350.000mil personas por mes y hasta octubre del 2021 se debería alcanzar la meta planteada. Lamentablemente este tema se ha visto eclipsado por el accionar para nada transparente que tuviera en su momento el Ministerio de Salud Pública con su principal a la cabeza el señor Zevallos. Las primeras 8.000 mil dosis de vacunas llegaron al país el 20 de enero del 2021, fueron recibidas por una comisión constituida por la Vicepresidenta de la Republica, el Ministro de Salud (Juan Carlos Zevallos-renunció a su cargo luego de las controversias no aclaradas por el proceso de vacunación) y como parte de esa comisión también el señor Juan Sebastián Roldan.

Luego el 17 de febrero del 2021 llegarían 16.380 dosis más. Es entonces donde se originaron una serie de irregularidades desde la cartera de estado antes mencionada, irregularidades que empañaron rotundamente este proceso, donde lo supuestamente planificado no se ejecutaría sino se incurrió en marcar una agenda totalmente distinta que estaría inundada de privilegios como por ejemplo a quienes se les empezaría suministrando las primeras dosis de la vacuna lo que dio como resultado los vacunados VIP en cuya listas aparecen desde familiares del exministro, periodistas, ministros de otras carteras de estado, algunos personajes "celebres y portadores del estandarte de la moralidad ecuatoriana" así como un par de You-tubers. Quedándose esto en el escenario mediático de las redes sociales y de uno que otro medio de comunicación, sin que nadie de la cara, sin que nadie rinda cuentas de lo sucedido. Hoy el país vive una especie de rebrote de la pandemia a causa de las variantes que según se indica la capacidad de contagio es mucho más veloz, el escenario de incertidumbre un año después no ha sido resuelto en este sentido y parece que a este ritmo tomará mucho tiempo en resolverse.

En el plano económico Ecuador ocupa el tercer puesto de las economías más afectadas de América Latina durante el periodo del 2020 solo por detrás de Perú y Argentina cuyas economías cayeron $12 \%$ y 10,6\% respectivamente. Diario El Comercio citando un informe del Banco Mundial menciona que la economía ecuatoriana tuvo una caída del 9,5\%. Esto se refleja por ejemplo en lo ocurrido a partir de septiembre del 2020 el desempleo afecto a medio millón de personas 7\% de la Población Económicamente Activa (PEA), así también se reflejaron 4,5millones de personas en la categoría de subempleo y tan solo 2,5millones de personas en empleo adecuado, mostrando que el trabajo informal dejó de ser algo coyuntural y pasó a convertirse en algo estructural.

La pobreza nacional por ingresos pasó $22,9 \%$ en 2016 al $25 \%$ en 2019 . Al termino del 2020 la tasa de pobreza se incrementó en 10 puntos, es decir 1,8millones de ecuatorianos pasaron a esa condición y 1,4 millones pasaron a condiciones de pobreza extrema (García, 2021).

El panorama se muestra incierto en este sentido para el país, se menciona en el informe que cita diario el comercio del Banco Mundial que la economía ecuatoriana probablemente crezca en un 3,5\% para este año 2021, cosa que estará sujeta a factores endógenos y exógenos del comportamiento económico y que se espera sea lo más alentador posible de tal manera que esto contribuya a bajar la carga de incertidumbre que por ahora arropa a la economía y se logren mejorar las condiciones laborales antes expuestas. 


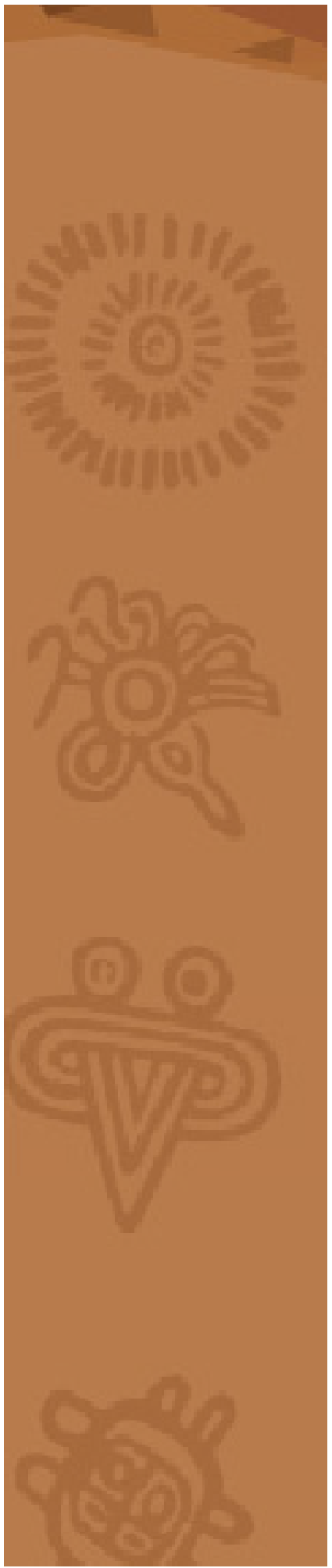

En Sociedad de la Incertidumbre primera parte se habló del escenario político que viviría el país al respecto de las elecciones presidenciales del 2021 . Para este momento ya se realizaron la primera y segunda vuelta electoral que trajo consigo algunas sorpresas en ese campo de batalla. El ganador de este primer momento fue el candidato del partido Unión por la Esperanza (UNES) quien obtuvo 3.033.753 votos es decir el 32,72\%, seguido del candidato de la Alianza Creando Oportunidades (CREO) -Partido Social Cristiano (PSC) quien saco 1.830 .045 votos es decir el 19,74\%. Pero cabe mencionar que en los primero días luego del proceso inicial de primera vuelta hubo una fuerte controversia entre el candidato Guillermo Lasso de la alianza (CREO-PSC) y el señor Yaku Pérez candidato del movimiento Pachakutik, esta discusión tenía como causa principal la falta de claridad existente en el proceso de conteo de votos y revisión de las actas, mismas que para ese momento reflejaban una separación mínima entre un candidato y otro, al final el candidato Pérez quedaría con el 19,39\% de la votación. El escenario de segunda vuelta electoral ocurrió el pasado 11 de abril dejando como ganador al candidato de la alianza (CREO-PSC) con el 52,36\% esto significa en votos (4.656.426) y el candidato Andrés Arauz de la coalición (UNES) quedaría con el 47,64\% (4.236.515) votos.

Esto demuestra que el Ecuador se mueve en las aguas pantanosas de la polarización política, aguas por las que tendrá que navegar y desde allí gobernar el candidato ganador durante los próximos cuatro años. Ahora bien las elecciones no solo eran para Presidente o Presidenta de la República, en este proceso también se elegirían a los y las asambleístas que conformarán parte del poder legislativo los próximos cuatro años. Esa elección es de carácter trascendental para cualquier candidato que quiera optar por ganar elecciones presidenciales, lograr contar con mayoría de asambleístas que comulguen con su proyecto de gobierno marca la cancha de la gobernabilidad. Aquí es donde precisamente aparece otro escenario de incertidumbre para el nuevo gobierno. Al finalizar la primera vuelta la asamblea quedó constituida de la siguiente forma: 49 asambleístas de Unión Por la Esperanza (UNES), 19 asambleístas por el Partido Social Cristiano y otras coaliciones, 18 asambleístas por la Izquierda Democrática, 27 por Pachakutik y 12 asambleístas por CREO. Demostrando esto que no hay una mayoría absoluta y que el fraccionamiento es la característica dominante en esta nueva constitución del legislativo, efecto que como se mencionó anteriormente deja sonando la bocina de la incertidumbre.

Cómo hacer un ejercicio adecuado de gobernabilidad desde el ejecutivo, cuál o qué cosas tendrán que ponerse en juego y en disputas para conseguir esa gobernabilidad, cuando, donde y entre quienes se originaran las alianzas, esas interrogantes empiezan a botear en los pasillos de la Asamblea. Indiscutiblemente la perspectiva es compleja frente a un escenario así, ya que esto puede llegar a debilitar al futuro gobierno, es decir que, cuando requiera implementar nuevos proyectos de ley o derogar alguno, hará que ese ejercicio sea mucho más complejo y quizás tome más tiempo llegar a los acuerdos mínimos y eso ubica al país en un lugar demasiado incomodo frente a la necesidad apremiante que el ecuador tiene para salir de los distintos atolladeros donde actualmente se encuentra, una circunstancia como esa puede llegar a determinar que el camino de salida de las crisis existentes se torne mucho más largo e incierto. 


\section{Conclusión.}

Definitivamente se pueden notar algunos desafíos que la región deberá enfrentar en los próximos años y que será necesario hacerlo de manera articulada, rápida y eficiente, no es posible salir de las actuales crisis de la forma como hasta ahora la región lo ha venido intentando, es decir aislada donde cada país ha intentado hacer lo suyo, desgastando y consumiendo sus esfuerzos sin notar avances y mejores resultados. América Latina ahora más que nunca necesita reencontrarse de manera regional como un bloque que le permita encontrar soluciones a denominadores comunes que están volviendo más complejo el reflotar de la región. El mismo proceso de vacunación pudo o podría enfrentarse de otra forma, es ahí donde se hacen necesario los liderazgos para una mejor gestión de esto que por ahora es lo más vital y de interés de todas y de todos los habitantes del continente. Los próximos años serán determinantes para América Latina, las estrategias regionales, las políticas y las relaciones que desde este lado se planteen con otras partes del hemisferio marcaran la guía de la salida a este escenario de crisis y de incertidumbre donde nos encontramos.

En Ecuador es prioritario recuperar la estabilidad política que se espera este nuevo periodo electoral y gobierno se la pueda garantizar, así mismo es de carácter urgente atender los temas que en este momento angustian a la mayoría de los ciudadanos, es necesario un adecuado programa de vacunación, que se trasparente y que tenga una hoja ruta clara de inicio a fin del mismo, la recuperación de la economía y con ella el empleo es otra de las prioridades para el país done ambos aspectos se conviertan en des-poseedores de toda angustia y se construyan las certezas a partir de su dinamización.

\section{Bibliografía.}

CNE https://elecciones2021.cne.gob.ec/

CEPAL (Marzo 2021) https://www.cepal.org/es/publicaciones/46687-panorama-social-america-latina-2020

Ecuador en cifras (2015) https://www.ecuadorencifras.gob.ec/documentos/web-inec/ ECV/ECV_2015/documentos/ECV\%20COMPENDIO\%20LIBRO.pdf

El Comercio (25 de enero 2021) https://www.elcomercio.com/actualidad/organismos-vigilancia-vacunacion-covid19-ecuador.html

El Comercio (18 de febrero 2021) https://www.elcomercio.com/actualidad/ecuador-vacuna-covid-proveedores.html

El Comercio (5 de enero del 2021) https://www.elcomercio.com/actualidad/banco-mundial-economia-ecuador-crecimiento.html

GK (19 de febrero 2021)https://gk.city/2021/02/19/nuevos-asambleistas/

MSP (21 de enero del 2021) https://www.salud.gob.ec/en-ecuador-inicio-la-vacuna- 


\section{Raíces}

Revista Nicaragüense de Antropología Año 5 No.9| 2021 Enero - Junio

cion-contra-la-covid-19/

Plan Vacunación (octubre 2020) https://www.salud.gob.ec/wp-content/uploads/2021/03/DOCUMENTO-PLAN-DE-VACUNACIO \%CC\%81N-ECUADOR-VS-FINAL_r.pdf

Primicias (21 de enero 2021) https://www.primicias.ec/noticias/sociedad/proceso-vacunacion-ecuador-opaco-region/

Primicias (20 de enero 2021) https://www.primicias.ec/noticias/sociedad/plan-piloto-vacuna-covid-ecuador/

Xavier Eduardo Perlaza Rodríguez

Sociólogo por la Universidad Estatal Salvador Allende de Guayaquil - Ecuador, cursa el Masterado en Cooperación Internacional Para El Desarrollo De Los Pueblos en la Universidad Tecnológica de México, así también cursa actualmente la especialización en Investigación Social en la Red de Investigadores Latinoamericanos (REDILAT). Escritor del artículo Sociedad de la Incertidumbre parte I, publicado recientemente en la segunda edición de la revista REDESS de la Escuela de Sociología de Sonora México. Ha dictado la catedra de Desarrollo Social en la Universidad Estatal Península de Santa Elena (UPSE), brinda asesoría y articula trabajos para ONG, actualmente es director y miembro fundador de Consultores Asociados del Ecuador. 